years ago. It has been revised and added to, especially in the sections about haemoglobinopathies and red cell enzymes, and chronic myeloid luekaemia has been awarded a separate chapter.

As in the previous edition this book gives a remarkably comprehensive, up to date, and concise but readable account of haematology. It can be recommended confidently to clinical undergraduates, and more senior students of general medicine may also find it useful.

\section{Recent Advances in Paediatrics, 3rd edition}

Edited by Douglas Gairdner. Pp. viii +349 ; 86 figures + tables. London: J. \&. A Churchill. 1965. 60s.

The latest publication in this well-known and popular series surpasses its predecessors. Here we have an outstanding collection of reviews and essays of contemporary interest and Dr. Douglas Gairdner, who again edits the volume, must be congratulated both on his selection of topics and choice of specialist contributors. The publishers deserve praise, too, for the attractive way in which the book is presented; also for supporting again, a production of this kind. At least half the work is devoted to recent advances in neonatal paediatrics and because of this emphasis the book can be recommended not only to paediatricians and intending specialists in this field but to all doctors whose practice brings them into contact with the newborn baby.

The Development of the Infant and Young Child: Normal and Abnormal

R. S. Illingworth. Third Edition. Pp. ix +378 with 164 illustrations. Edinburgh and London: E. \& S. Livingstone. 1966. $£ 1$ 17s. 6d.

The third edition of this outstanding book is even better than its predecessors. A vast amount of valuable information is packed into it and new material, including chapters on neonatal reflexes, maturity and assessment has added to its usefulness. The illustrative photographs are of excellent quality and most helpful, with the possible exception of figures 41 and 42 , which do not really show 'redressment du tronc.'

One could make a few criticisms. The author incorrectly defines dysmaturity as small in relation to the duration of gestation: the five minute Apgar score is in more general use than the three-minute score advocated: the paediatrician's role in adoption is to report on his assessment of the child, not to make decisions about suitability for adoption. These are small criticisms in a book of such general excellence, however, and no doctor concerned with developmental assessment can afford to be without it. It is a book to be read, re-read, and referred to constantly.

\section{Occupational Therapy in Rehabilitation}

Edited by E. M. MACDONALD with 23 Contributors. Second edition. Pp. $v+354$ illustrated. London: Balliere, Tindall \& Cox. 1964. 37s. 6d.

The first edition of this book was reviewed in this Journal on its publication in 1960 , and it is a tribute to the comprehensiveness and soundness of the 1st edition that so little has been amended or added in the second.

In her preface to the 2nd edition Miss Macdonald cites the following events as having wide influence on the "training application of occupational therapy in all spheres" - the setting up of the Council for the Professions Supplementary to Medicine in 1961, with the resultant State registration of Occupational Therapists commencing in September 1963 - and the publication of "A Hospital Plan for England and Wales" and the Mental Health Act of 1959.

In the section on "Basic Principles of Psychiatric Treatment" there is an interesting segment on a new conception of treatment - the therapeutic community - initiated and developed by Dr. Maxwell Jones. In this treatment the entire hospital community is involved, through informal ward meetings attended by staff and patients on equal terms, the patients being encouraged to open the discussion, and staff meetings in which staff enter into equally frank and uninhibited discussion, an attempt is being made to eliminate any elements of tension in the whole community because patients are affected by- disagreements between staff, although these may be consciously hidden. All occupational therapy programmes which aim to present the patients with the kind of problem they will meet when discharged are discussed at both meetings and agreed upon before being put into operation.

Another section where new knowledge has been brought to bear is that on children with psychological disorders. Here diagnosis is attempted through observation of the child's play, and in treatment emphasis is laid on "formation of a secure relationship with the therapist based on tolerance of a social behaviour, acceptance of his value as a human being and unconditional love." Of the two methods used in treatment it has been found that "patients are more productive in groups than in individual treatment, and in groups the therapeutic process is greatly accelerated."

In the section on "Mental Subnormality and Brain Damage" it is noted that "cases with minimal injury may be presented as behaviour problems," and here an Occupational Therapist trained in observation can be of great assistance.

The Bibliography has been enriched by some 36 books including the four volumes "Equipment for the Disabled" published by The National Fund for Research into Poliomyelitis.

\section{Immunopathology of Uveitis}

Edited by A. E. Maumensee, and A. M. SilverSTEIN. Pp. $x x+261$ illustrated. Baltimore: Williams and Wilkins; Edinburgh and London: E. \& S. Livingstone. 1964. $£ 816 \mathrm{~s}$.

The Council for Research in Glaucoma and Allied Diseases of the Alfred P. Sloan Foundation have held three symposia on uveitis, the present volume being the published transactions of the most recent one. The 2 participants, who included ophthalmologists, anatomists, immunologists, microbiologists, paediatricians, and pathologists, have contributed splendidly on immunopathology in general and also particularly as it relates to that ill-understood and troublesome condition, uveitis. This authoritative, well-edited and well-produced book is highly technical and of limited appeal to the general reader, but it is highly recommended to all postgraduates who are studying ophthalmology and immunology. 